\title{
A DIPSTICK SENSOR FOR COULOMETRIC ACID-BASE TITRATIONS
}

W. OLTHUIS, B. H. VAN DER SCHOOT, F. CHAVEZ* and P. BERGVELD

University of Twente, P.O. Box 217, 7500AE Enschede (The Netherlands)

\section{Abstract}

By performing an acid-base titration by coulometric generation of $\mathrm{OH}^{-}$ or $\mathrm{H}^{+}$ions at an inert electrode in close proximity to the $\mathrm{pH}$-sensitive gate of an ISFET, it is possible to determine the acid or base concentration of a solution using the ISFET as an indicator device for the equivalence point in the titration curve. Typical values for the titration time are 0.1 to $10 \mathrm{~s}$ for acid or base concentrations ranging from $0.5 \times 10^{-3}$ to $10 \times 10^{-3} \mathrm{~mol} / \mathrm{l}$.

By placing the counter electrode for the supplied current on the backside of a small piece of printed-circuit board on which the sensor-actuator is attached, we obtain a dipstick-like structure.

\section{Introduction}

In many applications, the ISFET pH-sensitive device offers a good alternative for the accurate but vulnerable $\mathrm{pH}$ glass electrode. The high impedance of the glass electrode and its construction are properties that make some applications difficult. For instance, in on-line monitoring of the blood pH during surgery, the small ISFET has already proven its advantage: new information becomes available for the surgeon, which cannot be obtained otherwise [1].

Another new mode of operation comes forward by using the small, planar and fast ISFET pH-sensor together with an actuator electrode [2]. By performing a coulometric acid-base titration in a submicrolitre volume in the proximity of the sensor, it is possible to determine the acid or base concentration of a solution.

In solutions of well-defined composition, the $\mathrm{pH}$ can be calculated from this measurement. If the nature of the protolyte is unknown, this relationship is more complicated. However, for some applications, such as in the food industry, it is desirable to obtain the total acid concentration instead of the $\mathrm{pH}$.

*Present address: Valle University, Department of Electrical Engineering, A.A. 25360, Cali, Colombia. 


\section{Operational mechanism}

The mechanism of the $\mathrm{pH}$ sensitivity of the ISFET is discussed elsewhere [3]. The accent in this paper lies on the actuator part of the coulometric system.

A schematic topview of the coulometric sensor-actuator system is presented in Fig. 1, showing the position and dimensions of the actuator electrode. When a current is applied to the actuator electrode into the solution, one of the following reactions takes place, depending on the direction of the current:

$$
\begin{aligned}
& 2 \mathrm{H}_{2} \mathrm{O} \longrightarrow 4 \mathrm{H}^{+}+4 e+\mathrm{O}_{2} \\
& 2 \mathrm{H}_{2} \mathrm{O}+2 e \longrightarrow 2 \mathrm{OH}^{-}+\mathrm{H}_{2}
\end{aligned}
$$

In this way the titrant is generated, making acid-base coulometric titration possible.

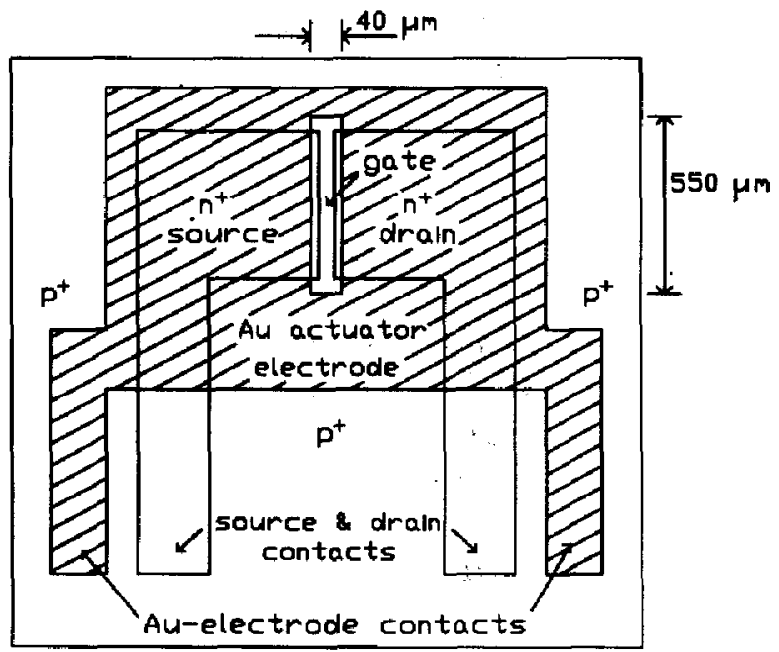

Fig. 1. Schematic topview of the coulometric sensor-actuator device.

Now consider the sensor-actuator system to be placed in an unstirred, alkaline aqueous solution with $\mathrm{p} K_{\mathrm{b}}<0$. At $t=0$ an anodic current pulse $i_{\mathrm{a}}$ [A] is applied to the actuator electrode, causing the generation of $\mathrm{H}^{+}$ions according to eqn. (1). Because of the very fast kinetics of the protolysis reaction of water, there will be a depletion of $\mathrm{OH}^{-}$ions near the actuator electrode surface, causing a concentration gradient of $\mathrm{OH}^{-}$ions. This gives rise to diffusion of $\mathrm{OH}^{-}$ions from the bulk solution towards the actuator electrode surface.

It is possible to present a simple expression of the $\mathrm{OH}^{-}$ion concentration $C_{\mathrm{OH}, \mathrm{es}}[\mathrm{mol} / \mathrm{l}]$ immediately at the surface of the actuator electrode, based on statistics of the mean square distance $\left\langle x^{2}\right\rangle$ that an ion travels in a 
given time interval and on the amount of generated ions $M_{\mathrm{H}}\left[\mathrm{mol} / \mathrm{m}^{2}\right]$ at time $t$ [s] after the start (at $t=0$ ) of the ion generation:

$C_{\mathrm{OH}, \mathrm{es}}(t)=C_{\mathrm{OH}, \mathrm{bulk}}-\frac{M_{\mathrm{H}}}{\sqrt{ }\left\langle x^{2}\right\rangle}=C_{\mathrm{OH}, \mathrm{bulk}}-\frac{i_{\mathrm{a} V} t}{F A \sqrt{2 D_{\mathrm{OH}}}}$

where $D_{\mathrm{OH}}$ is the diffusion coefficient $\left[\mathrm{m}^{2} / \mathrm{s}\right]$ of $\mathrm{OH}^{-}$ions, $A$ is the area $\left[\mathrm{m}^{2}\right]$ of the actuator electrode in contact with the solution, $F$ is Faraday's constant $\left(96.5 \times 10^{3} \mathrm{C} / \mathrm{mol}\right)$ and $C_{\mathrm{OH}, b u l k}[\mathrm{~mol} / 1]$ is the $\mathrm{OH}^{-}$bulk concentration. The equivalence point $t_{\mathrm{eq}}$ is reached in this symmetrical chemical system when $C_{\mathrm{OH}, \mathrm{es}}=1 \times 10^{-7} \mathrm{~mol} / 1$ (after which eqn. (3) loses its validity, 'because the excess-generated $\mathrm{H}^{+}$ions give rise to their own concentration gradient and diffusion).

As can be seen from eqn. (3), the time $t=t_{\mathrm{eq}}$ of the actuator current pulse needed to reach the equivalence point at the electrode surface is dependent on the bulk concentration $C_{\mathrm{OH} . b u l k}$ of the base.

Experiments and results

The ISFET is fabricated following the usual processing steps [4]. The actuator electrode used for the experiments mentioned here was made of a thin layer $(0.6 \mu \mathrm{m})$ of $\mathrm{Au}$ evaporated on an $\mathrm{Ag}$ and $\mathrm{Ti}$ layer for protection of the ISFET and good attachment of the film on the oxide, respectively. Using standard photolithographic techniques, the electrode was shaped as shown in Fig. 1. The area of the electrode in contact with the solution is determined by a polyimide mask, photolithographically patterned, which protects the rest of the device from the solution.

For our purpose, we glued the chip $(3 \times 4 \mathrm{~mm})$ on a piece of printed circuit board $(0.7 \times 10 \mathrm{~cm})$. A thin Au film evaporated on a Cu strip on the back-side of the printed circuit board served as counter electrode for the supplied actuator current.

The measurement set-up is shown in Fig. 2. A typical registration of a coulometric titration is shown in Fig. 3.

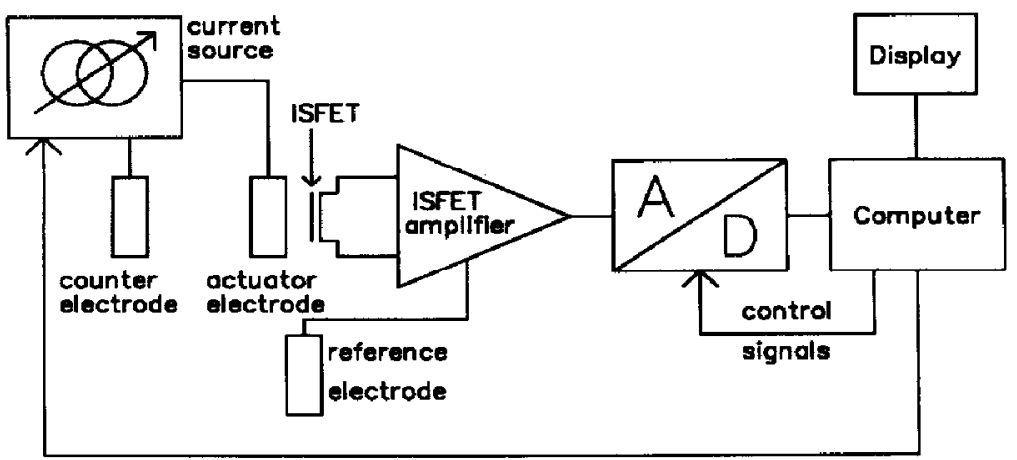

Fig. 2. Measurement set-up. 
The equivalence point $t_{\mathrm{eq}}$ is easily determined by the minimum of the first derivative of the titration curve. All measurements were done in a $50 \mathrm{ml}$ $0.1 \mathrm{M} \mathrm{KNO}_{3}$ background electrolyte. In order to test the device and verify the model as given in eqn. (3), we titrated a strong acid $\left(\mathrm{HNO}_{3}\right)$ and a strong 'base' $(\mathrm{NaOH})$ under the same conditions; the determined values of $t_{\mathrm{eq}}$ are shown in Fig. 4.

The difference in slope $\partial \sqrt{ } t_{\text {eq }} / \partial C$ of the two curves is, according to the model, due to the difference in diffusion coefficients of $\mathrm{H}^{+}$and $\mathrm{OH}^{-}$ions. The theoretical ratio between the two should be $\left(D_{\mathrm{OH}} / D_{\mathrm{H}}\right)^{1 / 2}=0.76$. The measured ratio of slopes is 0.75 .

The slope should also be inversely proportional to the applied actuator current $i_{\mathrm{a}}$, according to eqn. (3). The measured relation is given in Fig. 5. We found a ratio of 1.9 , while the theoretical ratio in slope is $20 \mu \mathrm{A} / 10 \mu \mathrm{A}=2$.

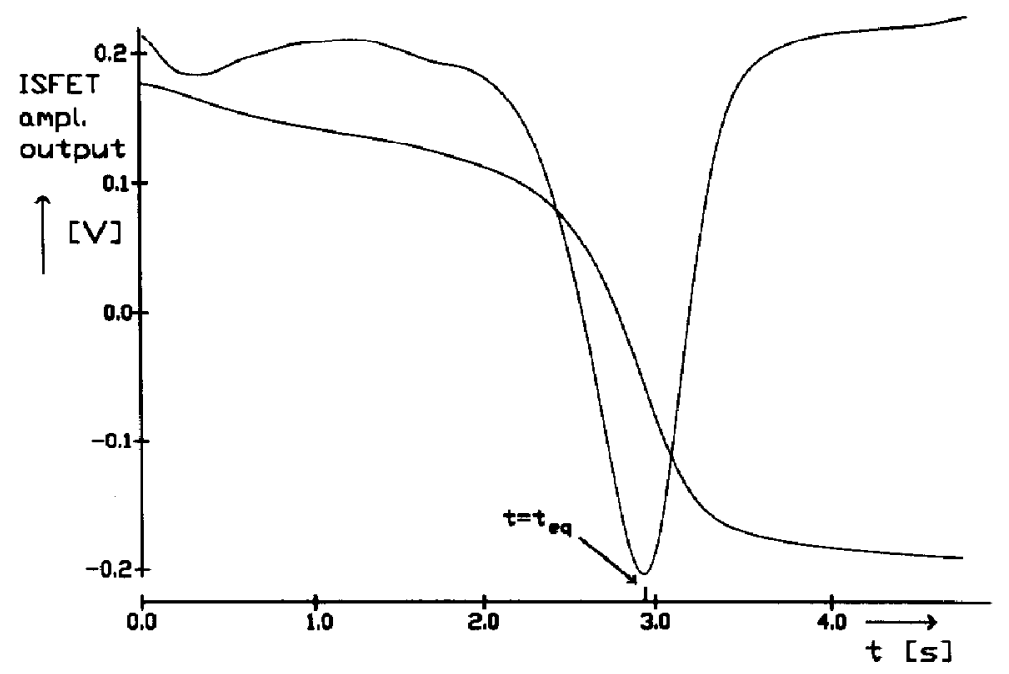

Fig. 3. Measured coulometric titration and its first derivative.

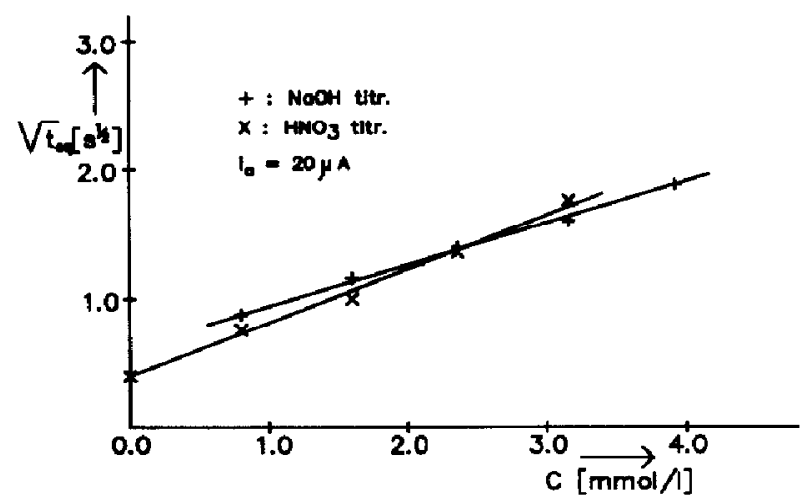

Fig. 4. Measured titration time us. $\mathrm{HNO}_{3}$ and $\mathrm{NaOH}$ concentration. 


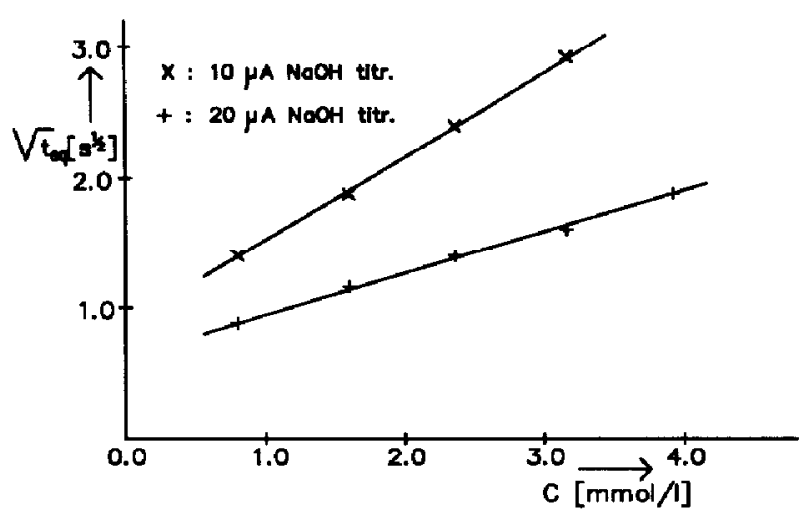

Fig. 5. Measured titration time us. $\mathrm{NaOH}$ concentration for two different actuator currents.

\section{Concluding remarks}

We described a sensor-actuator system for determining acid or base concentrations. For solutions with a well-defined composition, the $\mathrm{pH}$ can be calculated from this measurement. The measurements no longer depend on the static behaviour of the ISFET, including drift, but rely on free diffusion. The ISFET is only used as a fast (dynamic) indicator of the equivalence point. The measurements are in good agreement with the simple model presented here.

\section{Acknowledgement}

This investigation is part of the research program of the 'Stichting Fundamenteel onderzoek der Materie (FOM)', which is financially supported by the Nederlandse Organisatie voor Wetenschappelijk Onderzoek (NWO).

\section{References}

1 P. Bergveld, The development and application of FET-based biosénsors, Biosensors, 2 (1986) 15 - 33 .

2 B. van der Schoot and P. Bergveld, Coulometric sensors: ISFETs with a coulometric pH-actuator for long-term use without calibration, Digest of Techn. Papers, 4th Int. Conf. Solid-State Sensors and Actuators (Transducers '87), Tokyo, Japan, June 2 - 5 , 1987 , pp. 791 - 794.

3 L. J. Bousse, N. F. de Rooij and P. Bergveld, Operation of chemically sensitive fieldeffect sensors as a function of the insulator-electrolyte interface, IEEE Trans. Electron. Devices, ED-30 (1983) 1263 - 1270.

4 T. Matsuo and M. Esashi, Methods of ISFET fabrication, Sensors and Actuators, 1 (1981) 77 - 96. 